\title{
Sistem Informasi Ketersediaan Obat menggunakan Framework Laravel di Apotek Mugi Sehat Limpung Batang
}

\author{
Esti Astutik $^{1^{*}}$, Mustagfirin ${ }^{2}$ \\ ${ }^{1,2}$ Jurusan Teknik Informatika, Fakultas Teknik, Universitas Wahid Hasyim \\ Jl. Menoreh Tengah X/22, Sampangan, Semarang 50236. \\ *eztya19@gmail.com
}

\begin{abstract}
Abstrak
Keberadaan komputer saat ini sangatlah penting dalam pengolahan data. Karena teknologi komputer sangatlah membantu dalam mempercepat, mempermudah dan menciptakan keakuratan pengolahan data. Salah satunya dalam bidang kesehatan seperti farmasi yang sudah banyak menggunakan sistem informasi, didesain khusus untuk menangani berbagai lingkup inventory. Aplikasi yang dapat membantu proses inventory data obat Apotek Mugi Sehat saat ini belum diterapkan, persediaan data obat masih dilakukan dengan cara manual setiap melakukan pendataan laporan data barang masuk dan keluar masih menggunakan buku besar. Maka, perlu disediakan suatu sistem yang mampu mengelola data obat dengan terkomputerisasi tentu akan lebih memudahkan dalam pengelolaan ketersediaan obat. Penelitian ini bertujuan untuk menghasilkan aplikasi inventory (ketersediaan) data obat, yang nantinya dapat membantu mempermudah dalam menyajikan informasi persediaan data-data obat dan mempermudah pengelolaan sistem inventori obat dalam melakukan pendataan obat agar lebih efisien. Sistem ini dibangun dengan framework PHP yaitu Laravel versi 5.6 dan didukung dengan database MySQL untuk mengolah basis datanya. Hasil dari penelitian ini adalah sebuah Sistem Informasi Ketersediaan Obat Menggunakan Framework Laravel Di Apotek Mugi Sehat Limpung Batang.
\end{abstract}

Kata kunci: Inventory, Apotek, PHP, Framework laravel, MySQL

\section{PENDAHULUAN}

Apotek Mugi Sehat merupakan sebuah apotek yang sedang berkembang dalam membantu masyarakat dengan memberikan solusi dari berbagai macam penyakit-penyakit yang beredar di kehidupan sehari-hari. Pada sistem yang berjalan di Apotek Mugi Sehat saat ini masih bersifat konvensional yaitu di dalam kegiatan pencatatan obat masuk dan keluar masih menggunakan pencatatan sederhana pada pembukuan sebagai media dokumentasi, sehingga memakan waktu yang cukup lama pencatatannya apabila obat yang dibeli banyak. Pada saat transaksi penjualan harian konsumen harus menunggu ketika akan membeli obat, karena apoteker maupun asisten apoteker harus melihat terlebih dahulu stok obat yang tersedia pada daftar obat, sehingga mengakibatkan kurangnya optimalitas serta efektifitas kerja.

Selain itu dalam proses perhitungannya masih menggunakan alat elektronik kalkulator yang prosesnya harus menjumlahkan satu persatu harga obat yang harus dibayarkan oleh konsumen. Hal ini yang menjadi salah satu kendala yang ada di Apotek Mugi Sehat karena ada beberapa transaksi terjadi kekeliruan atau kesalahan di dalam proses perhitungan pembayaran oleh bagian kasir di saat apotek ramai didatangi konsumen. Pada saat akan membuat laporan penjualan, pembeli dan persediaan obat membutuhkan proses perhitungan yang banyak sehingga dibutuhkan ketelitian untuk menghindari kesalahankesalahan di dalam pembuatan laporan. Pada proses pencarian obat masih dilakukan dengan cara mencari satu persatu obat yang tersedia di catatan daftar obat bukan dengan penggunaan sistem aplikasi yang memiliki database di dalam komputer. Sehingga dapat menimbulkan peluang kesalahan dalam pencatatan, dan resiko human error yang dapat terjadi kapanpun.

Aplikasi yang dapat membantu proses inventory data obat Apotek Mugi Sehat saat ini belum diterapkan, persediaan data obat masih dilakukan dengan cara melakukan pendataan laporan data barang masuk dan keluar masih menggunakan buku besar. Maka, dibutuhkan suatu sistem yang mampu 
mengelola data obat dengan terkomputerisasi tentu akan lebih memudahkan dalam pengelolaan ketersediaan obat.

Penelitan yang berkaitan dengan sistem informasi inventori yang telah dilakukan sebelumnya yaitu dengan judul "Aplikasi Inventory Data Obat PT Hasil Karya Sejahtera Berbasis Web" (Ristanto, 2017). Tujuan dalam pembuatan website aplikasi inventori data obat tersebut yaitu, membuat sistem yang bisa digunakan untuk mendokumentasikan proses laporan data barang dan memberikan informasi kepada manajer mengenai data barang yang telah dilaporkan.

Berdasarkan penelitian sebelumnya pembuatan sistem aplikasi ini bertujuan menghasilkan aplikasi inventory (ketersediaan) data obat Apotek Mugi Sehat, yang nantinya mampu mengimplementasikan data-data obat dan laporan data obat agar dapat diolah dengan lebih cepat dan tepat sehingga mampu memberikan informasi yang akurat kepada user dan admin. Pembuatan sistem ini menggunakan Framework PHP yaitu Laravel yang merupakan Web Aplication Framework berbasis PHP yang Open Source, dan menggunakan konsep MVC (Model,View Controller). Dengan menggunakan UML (Unified Modeling Language) untuk pemodelannya, MySQL sebagai database server, dan dalam pengembangan sistemnya menggunakan metode waterfall.

Berdasarkan uraian latar belakang yang ada maka dirumuskan pokok permasalahannya yaitu :

1. Bagaimana cara menganalisa kebutuhan database persediaan obat pada apotek mugi sehat dengan baik?

2. Bagaimana membuat sebuah aplikasi sistem ketersediaan obat pada apotek mugi sehat berbasis laravel?

Agar penelitian ini tidak menyimpang dan mengambang dari tujuan yang semula direncanakan sehingga mempermudah mendapatkan data dan informasi yang diperlukan, maka ditetapkan batasan-batasan sebagai berikut:

1. Sistem informasi yang dibuat merupakan aplikasi berbasis web menggunakan framework laravel dan basis data MySQL.

2. Pembuatan aplikasi ketersediaan obat berbasis laravel ini dapat mengelola data obat, mengelola kasir dan data user atau pengguna.
3. Pembuatan aplikasi ketersediaan obat berbasis laravel ini dapat menangani pencatatan riwayat penjualan obat.

4. Aplikasi ketersediaan obat berbasis laravel ini juga hanya dapat mencetak laporan pendapatan data obat, dan mencetak laporan pengeluaran data obat.

\section{TINJAUAN PUSTAKA}

\subsection{Karakteristik Sistem}

Suatu sistem mempunyai model umum yaitu adanya input, proses, dan output. Hal ini merupakan konsep dari sebuah sistem, karena suatu sistem dapat mempunyai beberapa masukan dan beberapa keluaran. Di samping itu, sebuah sistem juga mempunyai karakteristik atau sifat-sifat tertentu yang menandakan bahwa hal tersebut dapat dikatakan sebagai sebuah sistem (Suyitno, 2017).

\subsection{Konsep dasar informasi}

Informasi sebagai sebuah data yang telah dilakukan pengolahan menjadi suatu bentuk yang lebih berarti serta berguna bagi penggunanya dalam pengambilan keputusan baik untuk masa kini atau yang akan datang (Rahmawati dan Bachtiar, 2018).

\subsection{UML (Unified Modeling Language)}

Menurut Handika, dkk (2018) Unified Modeling Language (UML) merupakan sistem arsitektur yang bekerja dalam OOAD (ObjectOriented Analysis/Design) dengan satu bahasa yang konsisten untuk menentukan, visualisasi, mengkontruksi dan mendokumentasikan artefact (sepotong informasi yang digunakan atau dihasilkan dalam suatu proses rekayasa software, dapat berupa model, deksripsi atau software) yang terdapat dalam sistem software.

\subsection{Model View Controller (MVC)}

Model-View-Controller atau MVC adalah sebuah metode untuk membuat sebuah aplikasi dengan memisahkan data (Model) dari tampilan (View) dan cara bagaimana memprosesnya (Controller) (Yudhanto dan Prasetyo, 2019).

\subsection{Laravel}

Laravel adalah salah satu framework PHP terbaik yang dikembangkan oleh Taylor Otwell, proyek laravel dimulai pada April 2011. Awal mula, proyek ini dibuat, karena Otwell sendiri tidak menemukan framework 
yang up-to-date dengan versi PHP. Laravel adalah sebuah framework PHP yang diliris dibawah MVC (Model view controller). Laravel adalah pengembangan website berbasis MVP yang ditulis dalam PHP yang dirancang untuk meningkatkan kualitas perangkat lunak dengan mengurangi biaya pengembangan awal dan biaya pemeliharaan, serta untuk meningkatkan pengalaman bekerja dengan aplikasi dengan menyediakan sintaks yang ekspresif, jelas, dan menghemat waktu. Laravel juga hadir sebagai platform web development yang bersifat open source (Yudhanto dan Prasetyo,2019).

\subsection{Waterfall}

Model SDLC air terjun (waterfall) sering juga disebut model sekuensial linier (sequential linear) atau alur hidup klasik (classic life cycle). Model air terjun menyediakan pendekatan alur hidup perangkat lunak secara sekuensial atau terurut dimulai dari analisis, desain, pengodean, pengujian, dan tahap pendukung (support) (Sukamto dan Shalahuddin,2016).

\subsection{Waterfall}

Model SDLC air terjun (waterfall) sering juga disebut model sekuensial linier (sequential linear) atau alur hidup klasik (classic life cycle). Model air terjun menyediakan pendekatan alur hidup perangkat lunak secara sekuensial atau terurut dimulai dari analisis, desain, pengodean, pengujian, dan tahap pendukung (support) (Sukamto dan Shalahuddin,2016).

\subsection{Bootstrap}

Bootstrap adalah paket aplikasi siap pakai untuk membuat front-end sebuah website. Bisa dikatakan, bootstrap adalah template desain web dengan fitur plus. Bootstrap diciptakan untuk mempermudah proses desain web bagi berbagai tingkat pengguna, mulai dari level pemula hingga yang sudah berpengalaman. Cukup bermodalkan pengetahuan dasar mengenai HTML dan CSS, anda pun siap menggunakan bootstrap (Christian dkk, 2018).

\section{METODE PENELITIAN}

\subsection{Bahan dan Materi}

Bahan dan materi yang digunakan dalam penelitian ini berupa data dari observasi lapangan berupa wawancara dengan pemilik
Apotek Mugi Sehat, serta penggunaan perangkat-perangkat komputer.

\subsection{Metode Pengembangan Sistem}

Dalam perancangan aplikasi ini, penulis mengimplementasikan metode Waterfall atau classic life cycle sebagai metode pengembangan perangkat lunak yang meliputi tahap :

1. Analisa Kebutuhan (Analysis)

2. Desain Sistem (Design)

3. Pemrograman (Coding)

4. Pengujian (Testing)

Pemodelan sistem dilakukan dengan menggunakan metode UML yang meliputi class diagram, usecase diagram, dan activity diagram.

\section{PERANCANGAN DAN IMPLEMENTASI 4.1 Perancangan Sistem}

Perancangan merupakan tahap yang harus dilakukan setelah tahap pengumpulan data, analisis data dan juga penentuan kebutuhan dari perangkat telah dilakukam sebelumnya. Dengan melakukan perancangan terlebih dahulu sebelum melakukan penerapan apa yang ingin dibuat merupakan langkah yang penting untuk nantinya digunakan dalam tahap awal untuk menentukan alur kerja dari sistem, mendesain tampilan antarmuka (user interface), mendesain database dan juga mendesain struktur source code dari sistem yang akan dibuat.

\subsection{Class Diagram}

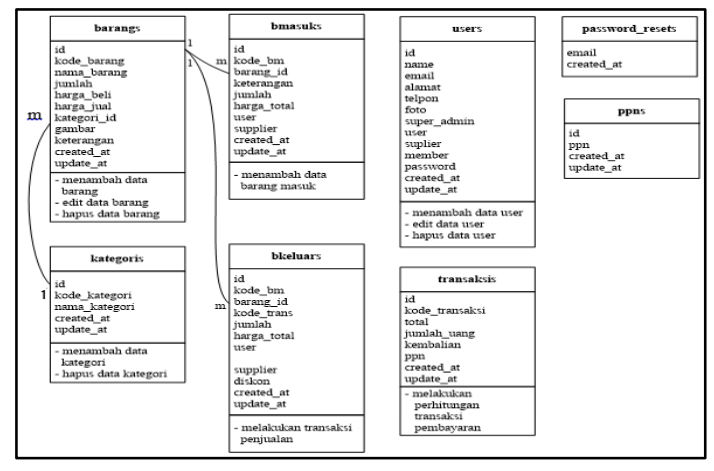

Gambar 1. Class Diagram

\subsection{Use Case Diagram}

Diagram use case adalah sebuah diagram yang menjelaskan apa yang harus dilakukan oleh sistem pada level konseptual sehingga kita akan memahami apakah 
keputusan yang diambil oleh sistem adalah benar atau tidak. Setiap use case menggambarkan perilaku sejumlah aspek sistem, tanpa mengurangi struktur internalnya.

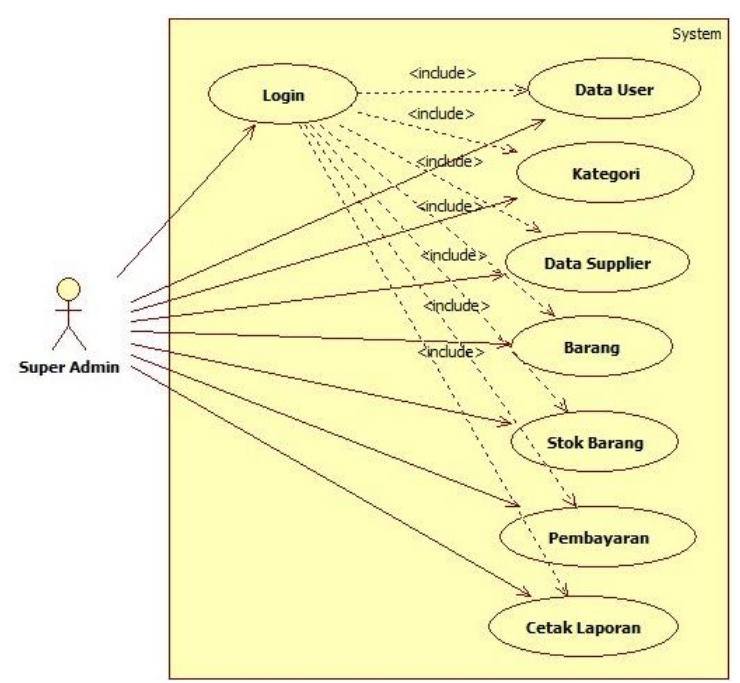

Gambar 2. Diagram Use case super admin

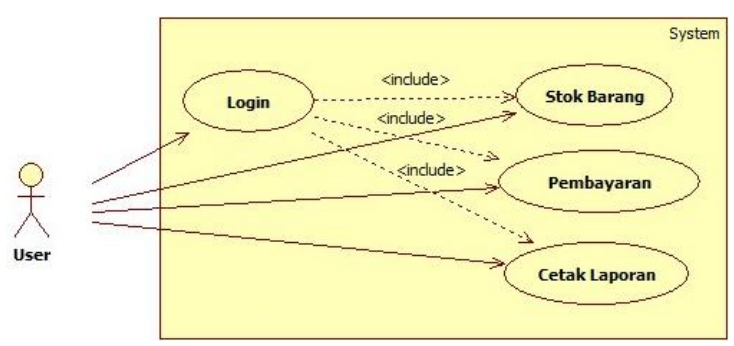

Gambar 3. Diagram Use case User

\subsection{Diagram Activity}

Diagram Activity menggambarkan berbagai alir aktifitas dalam sistem yang sedang dirancang, bagaimana alir berawal, keputusan yang mungkin terjadi, dan bagaimana berakhir.

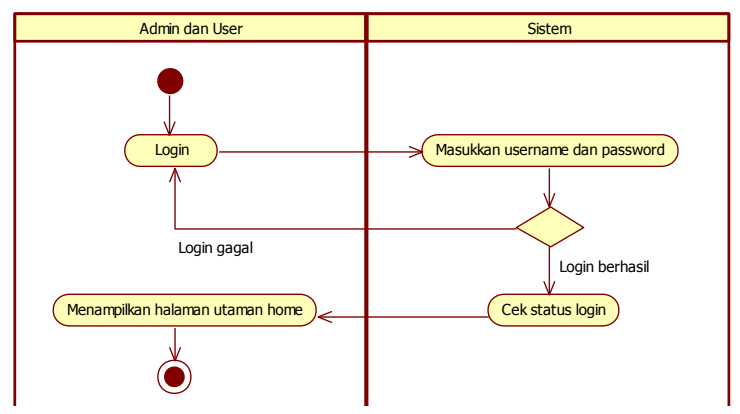

Gambar 4. Diagram Activity Login

Gambar 4 merupakan diagram activity dari halaman login, ketika user (pemilik dan apotek) memilih tombol mulai login, sistem akan menampilkan halaman login kemudian masukkan username dan password untuk mendapatkan hak aksesnya masing- masing.

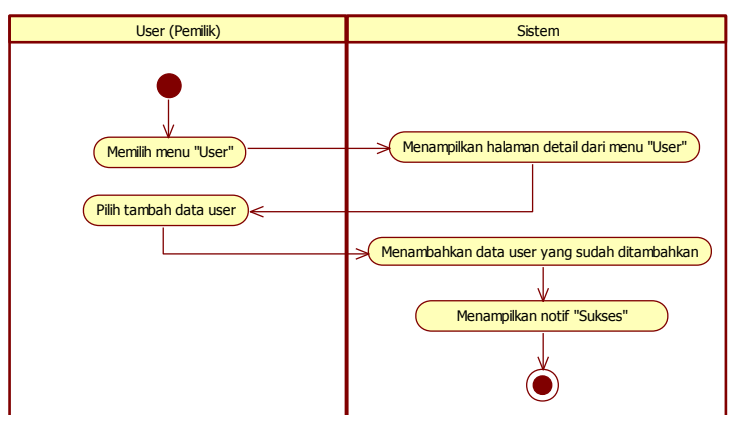

Gambar 5. Diagram Activity Tambah Data User

Gambar 5. merupakan diagram activity dari halaman user ketika pemilik memilih menu user, sistem akan menampilkan halaman detail dari data user. Kemudian pilih tambah user, fungsi pada sistem ini yaitu menambahkan data user.

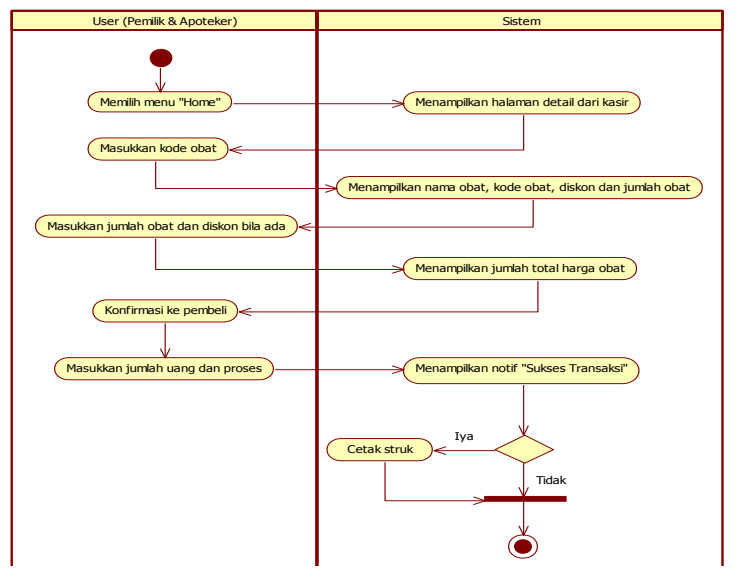

Gambar 6. Diagram Activity Kasir

Gambar 6. merupakan diagram activity dari halaman kasir, pemilik dan apoteker dapat mengakses form data penjualan atau kasir, fungsi pada sistem ini yaitu melakukan transaksi pembayaran obat di Apotek Mugi Sehat. 


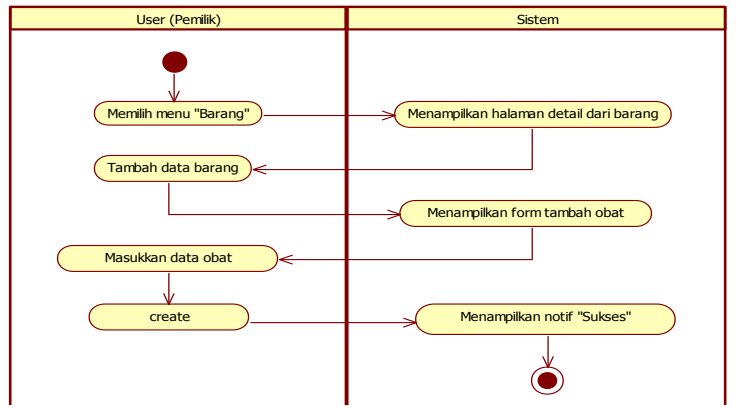

Gambar 7. Diagram Activuty Tambah Barang

Gambar 7. merupakan diagram activity dari halaman barang, pemilik dapat mengakses from data barang, fungsi pada sistem ini yaitu menambahkan data obat baru.

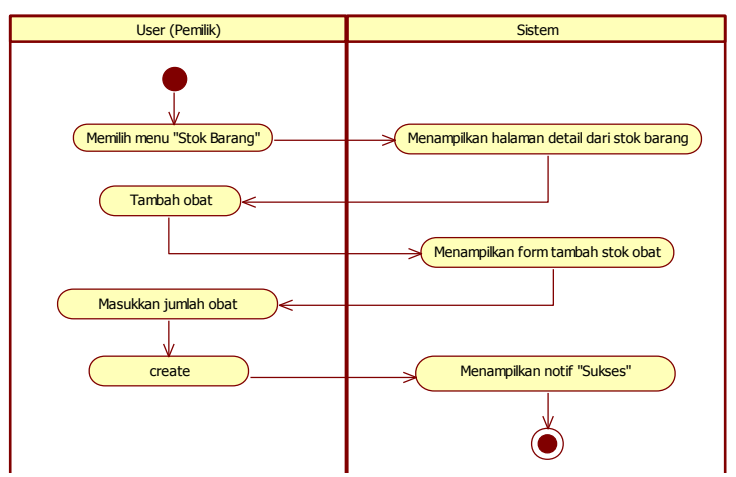

Gambar 8. Diagram Activity Tambah Stok Barang

Gambar 8. merupakan diagram activity dari halaman tambah stok barang, pemilik dapat mengakses form tambah data obat, fungsi pada sistem ini yaitu menambahkan jumlah stok barang atau obat.

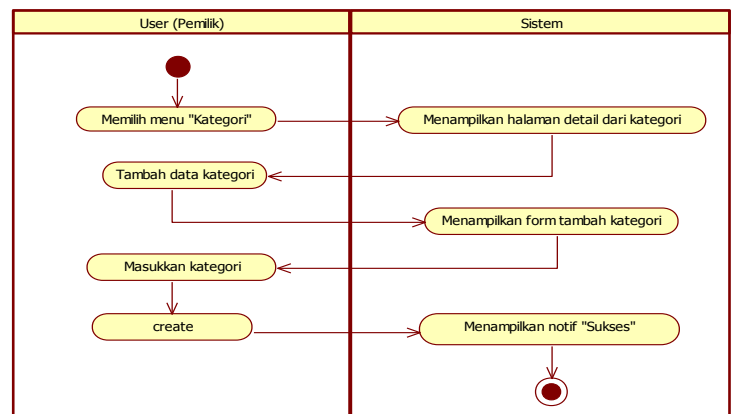

Gambar 9. Diagram Activity Kategori

Gambar 9. merupakan diagram activity dari halaman cetak laporan Apotek Mugi Sehat, pemilik dan apoteker dapat mengecek hasil dari data laporan pendapatan maupun laporan pengeluaran berdasarkan periode yang diinginkan.

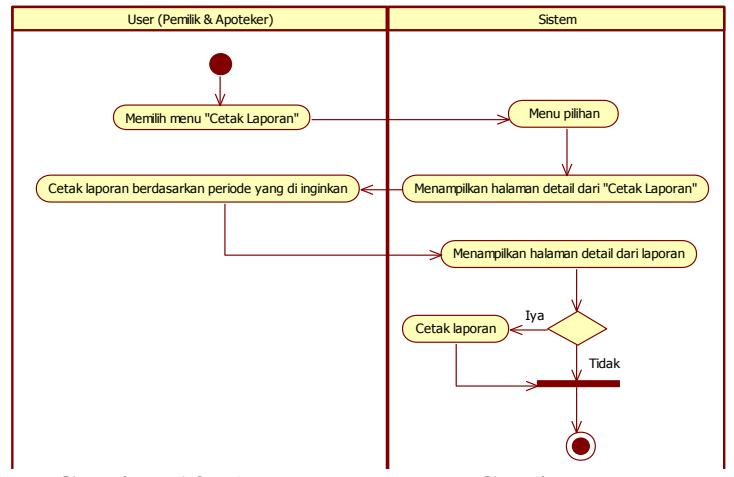

Gambar 10. Activity Diagram Cetak Laporan

Gambar 10. merupakan diagram activity dari halaman cetak laporan Apotek Mugi Sehat, pemilik dan apoteker dapat mengecek hasil dari data laporan pendapatan, laporan pengeluaran dan laporan obat berdasarkan periode atau kode kategori yang diinginkan.

\subsection{Pemodelan Data}

Entity Relationship Diagrams (ERD) merupakan salah satu model yang digunakan untuk mendesain database dengan tujuan menggambarkan data yang berelasi pada sebuah database, seperti yang ditunjukkan pada Gambar 11.

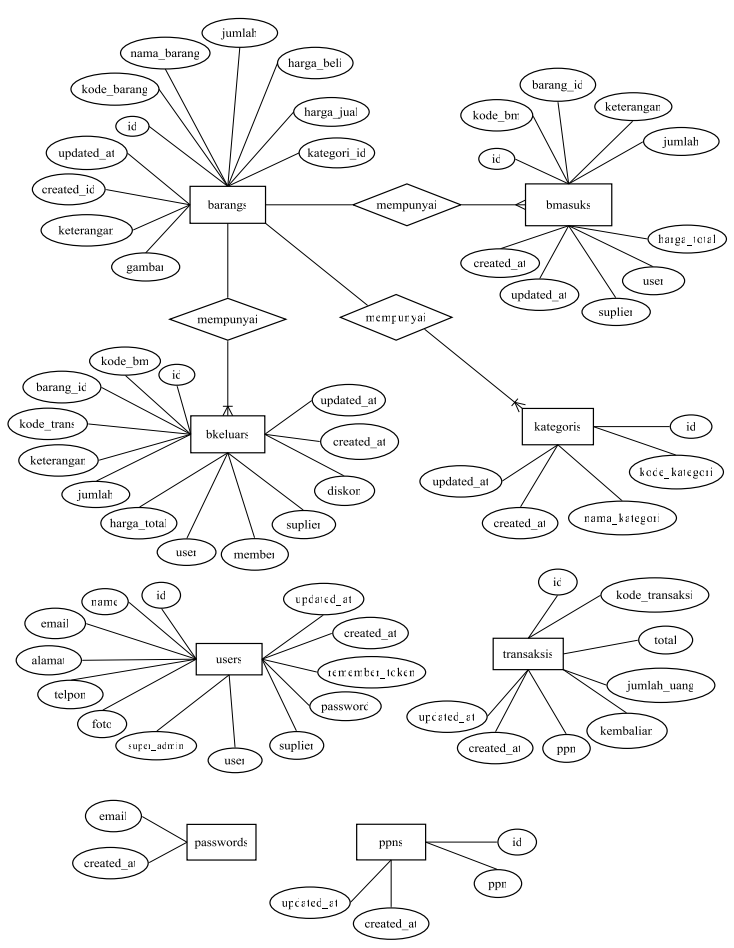

Gambar 11. ERD Sistem Informasi Ketersediaan Obat

HASIL DAN PEMBAHASAN

5.1 Struktur Aplikasi 


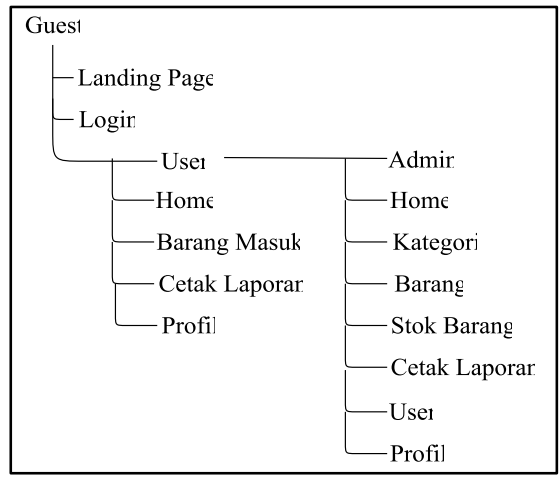

Gambar 12. Struktur Aplikasi

\section{a) Halaman Login}

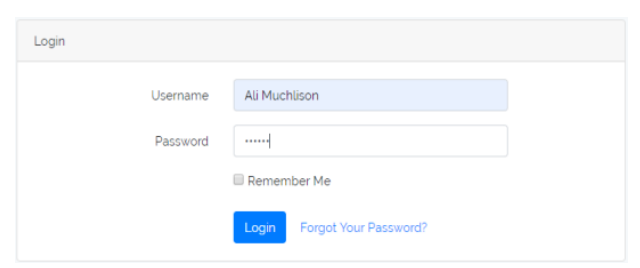

Gambar 13. Halaman Login

b) Halaman Pembayaran

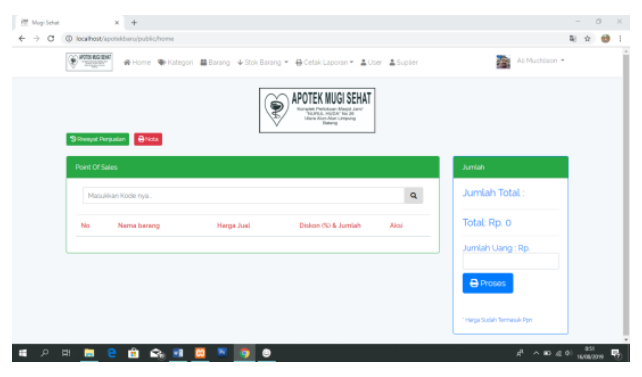

Gambar 14. Halaman Pembayaran

c) Halaman Cetak Laporan Pendapatan

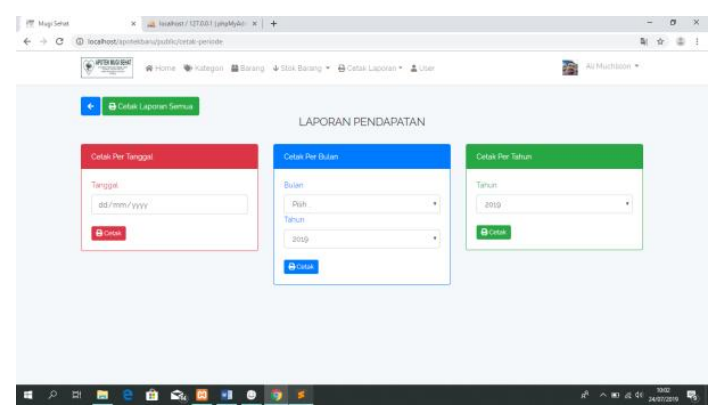

Gambar 15. Halaman Cetak Laporan Pendapatan

\section{KESIMPULAN DAN SARAN \\ 6.1 Kesimpulan}

Berdasarkan hasil pembahasan sebelumnya, maka dapat ditarik kesimpulan sebagai berikut:
1. Penelitian ini berhasil menganalisa kebutuhan database Apotek Mugi Sehat untuk dijadikan aplikasi sebagai bahan pembuatan Aplikasi ketersediaan obat.

2. Sistem Informasi Ketersediaan Obat Menggunakan Framework Laravel Di Apotek Mugi Sehat Limpung berhasil di bangun dengan menggunakan framework Laravel versi 5.6.

\subsection{Saran}

Terdapat beberapa saran dan masukan untuk pengembangan lebih lanjut dari sistem yang sudah ada agar memberikan hasil penelitian yang lebih baik. Berikut beberapa saran dan masukan untuk menunjang kesempurnaan sistem yang telah dikembangkan:

1. Dapat ditambahkan menu barcode scanner untuk mempermudah dalam scan produk obat sehingga nama/kode barang terinput dikomputer langsung guna mempercepat transaksi pembelian obat.

2. Diharapkan kedepannya Sistem Informasi Ketersediaan Obat Menggunakan Framework Laravel Di Apotek Mugi Sehat Limpung ini bisa dikembangkan lagi berbasis android.

\section{DAFTAR PUSTAKA}

Christian, A., Hesinto,S., Agustina., (2018), Jurnal SISFOKOM, Rancang Bangun Website Sekolah Dengan Menggunakan Framework Bootstrap (Studi Kasus SMP Negeri 6 Prabumulih), Volume 07, Nomor 01, Maret 2018.

Handika, I.G., dan Purbasari, A., (2018), Pemanfaatan Framework Laravel Dalam Pembangunan Aplikasi E-Travel Berbasis Website, Pangkalpinang, Konferensi Nasional Sistem Informasi 2018.

Rahmawati, N.A., dan Bachtiar, A.C., 2018, Analisis dan perancangan desain sistem informasi perpustakaan sekolah berdasarkan kebutuhan sistem, Berkala Ilmu Perpustakaan dan Informasi, Vol. 14 No. 1.

Ristanto, J., (2017), , Aplikasi Inventori Data Obat PT Hasil Karya Sejahtera Berbasis Web. Karya Ilmiah Mahasiswa Manajemen Informatika. http://eprints.jeb.polinela.ac.id/166/

Sukamto, R. A. dan Shalahuddin, M., (2016), Rekayasa Perangkat Lunak Terstruktur 
dan Berorientasi Objek, Informatika, Bandung.

Suyitno, (2017), Analisis Penerapan Sistem Informasi Manajemen Dan Kompetensi Pegawai Serta Pengaruhnya Terhadap Kinerja Pegawai, Journal of Business Administration, Volume 1, Nomor 2, September 2017, hlm. 124-133

Yudhanto. Y dan Prasetyo. H. A., (2019), Mudah Menguasai Framework Laravel. PT Elex Media Komputindo Kompas Gramedia. 